\title{
Influence of Eustachian tube function in the outcome of endoscopic type 1 tympanoplasty
}

\author{
${ }^{1}$ Niteshore MS, ${ }^{2}$ Rita Z, ${ }^{3}$ Kalpana Th D, ${ }^{4}$ Mohonish NC, ${ }^{5}$ Nicola CL, \\ ${ }^{6}$ Priyosakhi H D. \\ 1.2.3.4.5.6. (Dept. Of Otorhinolaryngology, Regional Institute of Medical Sciences, India)
}

\begin{abstract}
Context: Eustachian tube function has been regarded as a significant factor in the successful outcome of endoscopic type 1 tympanoplasty and resultant post-operative hearing gain.

Aims: The aim of this study is to evaluate hearing status in the pre-operative state and post-operative state after endoscopic type 1 tympanoplasty and to correlate the improvement with function of Eustachian tube of the patient.

Settings and Design: An interventional study carried out in the Department of Otorhinolaryngology, RIMS.

Methods and Material: 30 cases of diagnosed pars tensa central perforations, aged above 18 years, with a small to subtotal perforation associated with a demonstrable conductive deafness $\leq 40 \mathrm{~dB}$ was included in the study. Eustachian tube function was tested with valsalva test, seigalisation test, tonybee test and Impedance audiometry and nasal endoscopy.

Statistical analysis used: Chi Square test

Results: The overall graft uptake rate in our study is $90 \%$ and hearing improvement in terms of air-bone gap within 0-15 dB was achieved in 83.3\%. 28 (93\%) cases had a patent Eustachian tube out of these 89.3\% had a successful outcome whereas two (7\%) had a blocked Eustachian tube out of which $100 \%$ had an unsuccessful outcome.

Conclusions: The nonfunctioning of the eustachian tube were a significant determinant for the failure of type 1 tympanoplasty.
\end{abstract}

Key-words: endoscopic Type 1 tympanoplasty, endoscope, temporalis fascia, pure tone audiometry, Eustachian tube dysfunction.

\section{INTRODUCTION}

Various studies has given different views and results of the importance of the presence of a functioning eustachian tube in determining the outcome of type 1 tympanoplasty. The recent change of using endoscope instead of microscope in performing transcanal type 1 tympanoplasty has encouraged us to compare the results of the surgery in relation to the presence of functioning and non-functioning Eustachian tube. In this study, the main aim is to evaluate hearing status in the pre-operative state and compare it with the post-operative state and the graft uptake rate in patients with a functioning and non-functioning Eustachian tube after endoscopic type 1 tympanoplasty using various test like tuning fork test, pure tone audiometry, valsalva test, seigalisation test, tonybee test and Impedance audiometry and nasal endoscopy etc.

\section{Materials And Methods}

It is an intervention and observation study. The study was conducted with prior approval from Ethical committee of Regional Institute of Medical Sciences, Imphal, Manipur. The procedure and data collection was carried out for one and half calendar year, with effect from the month of September 2010. 30 patients suffering from pars tensa perforation of tympanic membrane aged above 18 years with demonstrable conductive deafness not more than $40 \mathrm{~dB}$ with complaint of decrease in hearing associated with tympanic membrane perforation without history of previous operation or a revision operation, tympanosclerosis, acute exacerbation of chronic otitis media (COM) or with purulent otorrhea, cholesteatoma, ossicular discontinuity, sensorineural hearing loss, cancer of head and neck, chronic cough or chronic obstructive pulmonary disease (COPD). Descriptive statistics like mean and percentage and analysis is carried out using statistical test like paired t- test, Chi square test etc.

The patients' hearing levels in decibel are assessed with a biologically calibrated Advanced Digital Audiometer AD 2100 at frequencies $250 \mathrm{~Hz}, 500 \mathrm{~Hz}, 1000 \mathrm{~Hz}, 2000 \mathrm{~Hz}, 4000 \mathrm{~Hz}$ and $8000 \mathrm{~Hz}$ respectively in an acoustically treated sound proof boot. Pre and postoperative pure tone average (PTA) and air-bone (A-B) gap were calculated and compared by taking the averages of bone conduction and air conduction at the frequencies of 500, 1000 and $2000 \mathrm{~Hz}$.

The functional testing of the eustachian tube was done with Valsalva test, tonybee test, pneumatic seigalisation and impedance audiometry, nasal endoscopy and duly recorded. 
Endoscopic tympanoplasty is typically performed via transcanal approach. Inspection of the ear canal and middle ear is performed using a four $\mathrm{mm}$ or $2.7 \mathrm{~mm} 0^{0}$ endoscope. Any abnormalities of the ear canal and tympanic membrane is examined and noted. The site, size, type of perforation and the ossicles are duly recorded. The opening of the Eustachian tube in the middle ear was examined and the condition recorded.

In this study, only the underlay technique was performed to provide similar ground for comparability. Antibiotics are given along with a mild pain reliever post operatively. Water is kept away from the ear, and nose blowing is discouraged. Patients are seen at two-three weeks to remove the packing from the external auditory canal and to ensure that adequate healing has begun. It is then determined whether or not the graft has fully taken. They are seen at six weeks to evaluate complete healing however final post-operative evaluation was made after an interval of six months.

\section{Results}

Hearing impairment - In this study hearing impairment means the patient with demonstrable conductive deafness not more than $40 \mathrm{~dB}$.

Successful outcome- An intact mobile tympanic membrane with closure of A-B gap less than or equal to $15 \mathrm{~dB}$ at six months post-operation was considered successful outcome.

Table 1: Success rate

\begin{tabular}{|l|l|l|}
\hline Success & No. of patient & Percentage \\
\hline Successful & 25 & 83.3 \\
\hline Unsuccessful & 5 & 16.7 \\
\hline Total & 30 & 100 \\
\hline
\end{tabular}

According to the criteria of success, $25(83.3 \%)$ had an overall successful outcome and five (16.7\%) patients had an unsuccessful outcome.

Table 2: Eustachian tube patency - success rate

\begin{tabular}{|l|c|c|c|}
\hline \multirow{2}{*}{ Eustachian Tube } & \multicolumn{2}{|l|}{ Success rate } & \multirow{2}{*}{ Total } \\
\cline { 2 - 4 } & Successful & Unsuccessful & 28 \\
\hline Patent & $25(89.3 \%)$ & $3(10.7 \%)$ & 2 \\
\hline Blocked & $0(0 \%)$ & $2(100 \%)$ & 30 \\
\hline Total & 25 & 5 & 30 \\
\hline
\end{tabular}

However when the function of the Eustachian tube is correlated with the outcome, 28 (93.3\%) cases had a patent eustachian tube with normal function out of which $10.7 \%$ had a successful outcome whereas two (6.6\%) had a blocked Eustachian tube out of which $100 \%$ had an unsuccessful outcome.

\section{Hearing result:}

The preoperative air conduction had a mean of $35.3 \pm 2.78 \mathrm{~dB}$ and the preoperative bone conduction had a mean of $6.61 \pm 2.71 \mathrm{~dB}$. The postoperative air conduction had a mean of $22.27 \pm 5.45 \mathrm{~dB}$ and the postoperative bone conduction value was $7.5 \pm 2.17 \mathrm{~dB}$.

Table 11: Preoperative air-bone gap and post operative air-bone gap

\begin{tabular}{|l|c|c|}
\hline & Preoperative air-bone gap & Post operative air-bone gap \\
\hline Mean & 28.7222 & 14.7222 \\
\hline $\mathrm{N}$ & 30 & 30 \\
\hline Std. Deviation & 3.65367 & 5.88985 \\
\hline Std. Error of Mean & .66707 & 1.07533 \\
\hline
\end{tabular}

There was an overall air-bone gap gain of $14 \mathrm{~dB}$ post-operatively.

\section{Discussion}

In the present study, a total of 30 cases diagnosed as pars tensa central perforations dry or non discharging for at least three weeks, aged above 18 years, with a small size to subtotal perforation, with a demonstrable conductive deafness not more than $40 \mathrm{~dB}$, and willing for surgery and consented to participate in the study procedure underwent type 1 tympanoplasty. The patients were followed for period of 6 months.

Non functioning eustachian tube was found in two (6.6\%) cases and a functioning eustachian tube was found in $28(93.4 \%)$ cases. All the cases with a blocked eustachian tube had a failure rate of $100 \%$. This finding shows a significant relationship between the non functioning eustachian tube and failure of the surgery. This 
finding is in agreement with the findings of Chopra $\mathrm{H}$ et al[1] and William O. Collins et al [2]. However M. Tos et al[3] reported that eustachian tube function seemed to have no importance for reperforation.

As the data suggested, the overall success rate is $83.3 \%$ in this study. The overall success rate and the graft uptake rate is comparable to the value given in some literature. Mani Lal Aich and co-worker[4] reported an overall graft take rate was $84 \%$. The mean preoperative and postoperative air conduction threshold in the successful cases was $35.2 \mathrm{~dB} \& 24.1 \mathrm{~dB}$ respectively with a mean audiological improvement of $11.1 \mathrm{~dB} \&$ air bone gap improvement was $12.4 \mathrm{~dB}$. Yadav SPS et al[5] had an overall success rate of $80 \%$. The successful outcome rate of Haruqop A et al ( $82 \%$ endoscopic vs $86 \%$ microscopic) are comparable to the outcome of this study.

The overall graft uptake rate of $90 \%$ in our study is comparable to the success reported by Anoop Raj and Ravi Meher[6] (90\% for endoscopic vs 85\% in microscopic group) and Ashfaque Ahmed Shaikh et al[7] $(81 \%)$. When it is correlated with the function of Eustachian tube, all the patients $(100 \%)$ with a non-functioning Eustachian tube had failed to take up the graft. This shows that the presence of a normal functioning Eustachian tube is an important determinant in the outcome of the surgery.

\section{Conclusion}

The importance of Eustachian tube function in the outcome of endoscopic type1 tympanoplasty was studied by some author. However there were conflicting reports regarding its importance. We have attempted a similar study in an attempt to bring out the clearer picture of its role and importance. As our study result shows, there is a significant role of functioning Eustachian tube in the successful outcome of endoscopic type 1 tympanoplasty.

\section{Acknowledgement}

We are indebted to our teachers who guided us in the study as ear surgeons and ENT consultants. Thanks are also due to the local audiometry assistants and staff in the department of Otorhinolaryngology that took part in this study.

\section{References:}

[1] Chopra H, Gupta S, Munish M. Correlation between eustachian tube functions and result of myringoplasty. IJO \& HNS 1994 JulSep;3(3):149-51.

[2] William O. Collins, Fred F. Telischi, Thomas J. Balkany, Craig A. Buchman. Pediatric Tympanoplasty: Effect of contralateral ear status on outcomes. Arch Otolaryngol Head Neck Surg 2003;129:646-51.

[3] M. Tos, S.E. Stangerup and S. Orntoft. Reasons for reperforation after tympanoplasty in children. Acta Otolaryngol 2000;543:14346.

[4] Mani Lal Aich, ABM Khorshed Alam, Debesh Chandra Talukder, Abdullah Al Harun, M. Abdullah. Outcome of myringoplasty. Bangladesh J Otorhinolaryngol 2009; 15(2): 40-44.

[5] Yadav S P S, Aggarwal N, Julaha M, Goel A. Endoscope-assisted myringoplasty. Singapore Med J 2009;50(5):510-12.

[6] Anoop Raj, Ravi Meher. Endoscopic trans canal myringoplasty-A study. IJO \& HNS 2001 Jan-mar;5(1):47-49.

[7] Ashfaque Ahmed Shaikh, M. Shuja Farrukh, Salman Mutiullah, Tariq Rafi, Maisam Abbas Shiraz Onali. Audiological results of Type I Tympanoplasty by underlay technique with temporalis fascia graft. Pakistan journal of Otolaryngology 2009;25:30-31. 